\title{
A STUDY ON IMMUNIZATION OF CHILDREN AT URBAN HEALTH TRAINING CENTRE IN UDAIPUR CITY, RAJASTHAN
}

\begin{tabular}{ll} 
Dr Ānjili Mathur & $\begin{array}{l}\text { Associate Professor, Dept of Community Medicine, RNT Medical College, } \\
\text { Udaipur }\end{array}$ \\
\hline Dr Ānum Fatima* & $\begin{array}{l}\text { Resident Doctor, Dept of Community Medicine, RNT Medical College, } \\
\text { Udaipur. }{ }^{*} \text { Corresponding Author }\end{array}$ \\
\hline Dr Äbhinav Vyas & Junior Resident,Abhinav Bal Chikitsalaya,Abu road,Sirohi \\
\hline $\begin{array}{l}\text { Dr Anuradha } \\
\text { Meena }\end{array}$ & $\begin{array}{l}\text { Resident Doctor,Dept of Community Medicine, RNT Medical College, } \\
\text { Udaipur }\end{array}$ \\
\hline $\begin{array}{l}\text { Dr Shruti } \\
\text { Priyadarshini }\end{array}$ & MBBS
\end{tabular}

ABSTRACT Background: Immunization is the most economic and most efficient solution to prevent children from infectious diseases. Despite launch of several programmes by the government, parents attitude and knowledge towards vaccination is what matters most. Objective:(i) To study immunization related details of children in general population of UHTC. (ii) To counsel mothers regarding immunization. Methodology: A questionnaire based cross sectional study was conducted for 2 month duration (August and September 2020) among 100 mothers who visited general outdoor of a UHTC in Udaipur city.Data was entered in MS Excel and analysed through SPSS. Result: Majority of the mothers were of the age group 21-25 years (56\%), educated upto secondary school (49\%), were housewives / unemployed (46\%). The source of information for the maximum participants were health workers. Majority chose government set ups for vaccination of their children (91\%).Among all, 69\% were fully immunized,30\% were partially immunized and only $1 \%$ were not immunized at all. An overall $38 \%$ drop-out rate was seen. The most common reason of non-vaccination was found to be fear of side effects among the parents (37\%).Conclusion: Active and comprehensive involvement of sociologists, behavioural scientists and health personnel is very important to produce effective changes in the attitudes and practices regarding immunization of children.

KEYWORDS : Immunization,vaccination,mothers, children

\section{INTRODUCTION:}

Children are the future of any country so their development is as significant as the development of other assets. Immunization is a vital part for the proper development of the children. Immunization is an easy, secure and efficient process of protecting individuals against the world's most infectious diseases by administering vaccines. ${ }^{1}$ Immunization process will become more successful if the child receives full course of recommended immunization doses. ${ }^{2}$ Immunization is the most economic and most efficient solution to prevent children from infectious diseases. ${ }^{3}$

The World Health Organisation (WHO) launched the expanded programme on immunisation (EPI) in 1974 with the aim of immunising children throughout the world. The programme uses proven strategies, like outreach services, to ensure delivery of vaccines even to the most hard-to reach and vulnerable populations. ${ }^{4}$ The historical success of eradicating the dreaded disease, Smallpox, prompted World Health Organization (WHO) to ask its member countries to launch immunization against six vaccine preventable diseases in its national immunization schedule. In May 1974, the WHO launched the Expanded Programme on Immunization (EPI) globally, with focus on prevention of 6 vaccine-preventable diseases by the year 2000. In India, EPI was launched in 1978 and it was re-designated as the Universal Immunization Programme (UIP) in $1985 .{ }^{5}$ Government of India launched Mission Indradhanush ,Intensified Mission Indradhanush and Intensified Mission Indradhanush 2.0 respectively in years 2014, 2017 and 2019 to boost immunization coverage in India. ${ }^{6}$ As per NFHS 4, 2015-16, in India the national average for full immunization is 62 per cent, DPT-3 coverage - 78.4 per cent and for measles first dose - 81.1 per cent.

There are many factors that play important role in immunization status of a child which we are going to address in this study.

\section{METHODOLOGY:}

STUDY DESIGN: A community based cross sectional study was conducted over a period of two months; AugustSeptember 2020 using a semi structured, self designed questionnaire.

STUDY AREA: Study was conducted at Urban Health Training Centre located at Dhanmandi, Udaipur which is affiliated to RNT Medical College,Udaipur.

\section{STUDY POPULATION:}

Mothers of children aged 12-23 months who visited the outdoor of the UHTC during the study period were included in the study. After explaining the purpose of the study to the mothers oral consents were taken. Mothers who did not give consent were excluded from the study. Information was collected by using semi structured proforma. ${ }^{8,9}$ Accuracy of immunization data was improved by checking the immunization cards, and when cards were unavailable, mothers' reports on children having been given/ not been given a vaccine was recorded.

ANALYSIS OF DATA: The data was tabulated using Microsoft Excel, figures were converted into percentage and then analyzed using the SPSS.

\section{RESULT:}

A total of 100 children in the age group of 12 to 23 months were included in the study and their mothers were questioned. This sample included 48 boys and 52 girl children.

Majority of the mothers were of the age group 21-25 years $(56 \%)$, followed by less than or equal to 20 years (21\%), $26-30$ years ( $17 \%), 31-35$ years $(6 \%)$.None of them was more than 36 years of age. 
Most mothers were educated upto secondary school (49\%), followed by upto primary school (22\%). $20 \%$ were illiterate. $5 \%$ were graduates and $4 \%$ studied upto senior secondary.None of them was post graduate.

Majority of the mothers were housewives / unemployed (46\%) .As per occupation the second most common group was of daily wagers (40\%); and $14 \%$ were employed on monthly salary basis. [Tablel].

Table 1: Distribution of Socio-demographic indicators of the respondents

\begin{tabular}{|l|l|l|}
\hline S.No & SOCIODEMOGRAPHIC INDICATOR & N (\%) \\
\hline 1 & AGE OF THE MOTHER & $21(21)$ \\
\hline & $\leq 20$ years & $56(56)$ \\
\hline & $21-25$ years & $17(17)$ \\
\hline & $26-30$ years & $06(6)$ \\
\hline & $31-35$ years & $0(0)$ \\
\hline & $36-40$ years & $0(0)$ \\
\hline & $>40$ years & $20(20)$ \\
\hline 2 & EDUCATION STATUS OF THE MOTHER \\
\hline & Illiterate & $22(22)$ \\
\hline & Primary school & $49(49)$ \\
\hline & Secondary school & $4(4)$ \\
\hline & Senior secondary school & $5(5)$ \\
\hline & Graduation & $0(0)$ \\
\hline & Post graduation & $46(46)$ \\
\hline 3 & OCCUPATION OF THE MOTHER & $40(40)$ \\
\hline & Unemployed/ Housewife & $14(14)$ \\
\hline & Daily wage & \multicolumn{1}{|l|}{} \\
\hline & Employed
\end{tabular}

The source of information regarding immunization for the maximum number of participants were health workers like auxillary nurse midwives (ANM) and anganwadi workers (AWW),(34\%);followed by doctors (30\%). Majority chose government set ups for vaccination of their children (91\%), and only $9 \%$ went to private set ups.

Among all, 69\% were fully immunized,30\% were partially immunized and only $1 \%$ were not immunized at all. (A child is said to be fully immunized if child receives all due vaccine as per national immunization schedule within lst year of life. ${ }^{10} \mathrm{~A}$ child who had missed any of the vaccines given under the national immunization programme till one year of age is classified as partially-immunized while those who had not received any vaccine up to 12 months of age or received only pulse polio vaccine are classified as non-immunized. ${ }^{11}$ )

[Table 2]

Table 2: Immunization details of the children

\begin{tabular}{|l|l|l|}
\hline S.No & IMMUNIZATION DETAILS & N (\%) \\
\hline 1 & SOURCE OF INFORMATION & $34(34)$ \\
\hline & Health worker (ANM/AWW) & $30(30)$ \\
\hline & Doctor & $25(25)$ \\
\hline & Family or friends & $4(4)$ \\
\hline & Neighbours & $7(7)$ \\
& $\begin{array}{l}\text { Mass media (Television/ posters/ banners } \\
\text { etc) }\end{array}$ & \multicolumn{2}{|l|}{} \\
\hline 2 & PLACE OF IMMUNIZATION & $91(91)$ \\
\hline & Government & $9(9)$ \\
\hline & Private & $69(69)$ \\
\hline 3 & IMMUNIZATION STATUS & $30(30)$ \\
\hline & Fully immunized & $1(1)$ \\
\hline & Partially immunized &
\end{tabular}

Majority of the participants (74\%) had the knowledge that disease could be prevented by immunization. Though among these only $59 \%$ had fully immunized children. No participant could name more than 4 diseases that could be prevented by the vaccines, while $31 \%$ could not name even one.
An overall $38 \%$ drop-out rate was seen among the participants. Maximum drop out was seen specifically for the $10^{\text {th }}$ week scheduled immunization which consists of vaccination with Pentavalent $-2^{\text {nd }}$ dose, Rotavirus- $2^{\text {nd }}$ dose, Oral poliovirus- $2^{\text {nd }}$ dose; second most common drop out was seen for immunization scheduled at 16-24 months, which consists of vaccination with DPT- ${ }^{\text {st }}$ booster dose, Oral poliovirus -booster dose,MR- ${ }^{\text {nd }}$ dose and vitamin-A drops. ${ }^{12}$

The most common reason of non-vaccination was found to be fear of side effects among the parents (37\%), and the most common side effect feared was fever.23\% of the participants liked their children to be vaccinated but were unaware about schedule and thus missed vaccination because of being late.[Figure 1]

\section{Figure 1: Reason of non-vaccination}

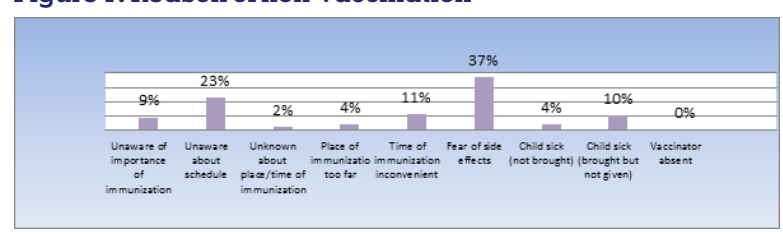

After being counselled, most of the mothers showed positive attitude towards vaccination with a pledge of getting their children fully immunised according to the schedule and also spreading awareness about benefits of vaccination among their families, neighbours and friends.

\section{DISCUSSION:}

Immunization of children is the bridge to healthy next generation of a country.In developing countries like India,focus of the policy makers should be not only on initiating immunization programmes but also on their proper implementation and motivation among the community to follow it on a regular basis.

Similar to our study, a study conducted in Sudan ${ }^{13}$ showed that for most of the mothers the main source of information about vaccination were health workers. Also a study conducted in North India reported paramedics to be main source of information. But in a study of Karnataka, India ${ }^{4}$ family of the participants was the main source of information. The study of Sudan $^{13}$ also reported poor knowledge among mothers about the names of the vaccines and diseases prevented by them; similar to our study. This may be because of the reason that health workers pay more attention at informing the parents about next vaccine's date and not educating them about the details like its benefits and side effects.

Similar to our study, the study in Karnataka ${ }^{4}$ showed that majority of people chose government set ups for vaccination which may be the result of several government policies and their cost effectiveness. This study showed most common reason of non-vaccination to be lack of knowledge regarding schedule (97\%), unlike our study which showed fear of side effects among the parents (37\%) to be the most common reason.

Maximum drop outs in a study of Karnataka ${ }^{4}$ and Rajasthan, India $^{14}$ were seen for DPT-3 and OPV-3.While in the study of Sudan $^{13}$ they were found out to be of BCG.This may be because of more number of home deliveries.

\section{CONCLUSION:}

Mothers play a vital role in immunization status of children of a country.Their knowledge and perceptions are very important. Health workers need to be trained not only for skill of applying a vaccine or vaccination schedule but also for counselling of the community. Thus what matters most is active and comprehensive involvement of sociologists, 
behavioural scientists and health personnel to produce effective changes in the attitudes and practices regarding immunization of children.

\section{REFERENCES:}

1. The UNICEF website. Available: http://www.unicef.org/immunization/

2. Mohitulameen Ahmed Mustafi and Dr. Mir Mohammad Azad, "Factor Influencing of Child Immunization in Bangladesh" International Journal of Mathematics and Statistics Studies, vol. 1, no. 3, pp. 55-65, September 2013

3. Child Immunization Coverage-A critical review; Available at: https:// www. researchgate. net/publication/309223196

4. M. M. Angadi et al., Study on KAP of Immunization in Urban Slums of Bijapur City. Journal of Clinical and Diagnostic Research. 2013 Dec, Vol-7(12): 28032806

5. Park K. Park's textbook of Preventive and Social Medicine, Banarsidas Bhanot Publishers. 22nd Edition, 2009; 114

6. https://www.nhp.gov.in/mission-indradhanush

7. UNICEF website: https://www.unicef.org/india/what-we-do/immunization Last assesed on 15 October 2020

8. WHO website: https:// www. who. int/ immunization/ programmes systems/ Survey Questions Hesitancy.pdf

9. Qutaiba Omer \& Al-lela Omer Q.B. \& Bahari, mohd baidi \& Alabbassi, Mustafa \& Basher, Amena. (2011). Development of a questionnaire on knowledge, attitude and practice about immunization among Iraqi parents. Journal of Public Health. 19. 497-503. 10.1007/s10389-01 1-041 1-9.

10. https://nhm.gov.in/indexl.php?lang $=1$ \&level $=2 \&$ sublinkid $=824 \&$ lid $=220$

11. https://www. ncbi. nlm. nih. gov/pmc/articles/PMC 2980896/ \# : : text = A\% 20 child $\% 20$ who $\% 20$ had $\% 20$ missed , were $\% 20$ classified $\% 20$ as $\% 20$ non $\% 2$ Dimmunized.

12. According to National Immunisation Schedule (NIS) of India. Available at https://main.mohfw.gov.in/sites/default/files/245453521061489663873.pdf

13. Ali AHM, Abdullah MA, Saad FM, Mohamed HA. Immunisation of children under five years:mothers' knowledge, attitude and practice in Alseir locality Northern State, Sudan. Sudan J Paediatr. 2020:20(2):152-162. Available at https://doi.org/10.24911/SJP.106-1586870453

14. Manjunath U, Pareek RP. Maternal knowledge and perceptions about the routine immunization programme - A study in a semi-urban area in Rajasthan. Indian J Med Sci. 2003; 57:158-63. 